\title{
ENCEFALITIS ASOCIADA A ANTICUERPOS CONTRA LOS RECEPTORES NMDA: REPORTE DE CASO
}

\author{
E N C E P H A L I T I S \\ ASSOCIATED WITH \\ ANTIBODIES AGAINST \\ NMDA RECEIVERS: CASE \\ REPORT
}

\section{Ana M. Álvarez Sanz Lizeth Y. Cabanillas Burgos ${ }^{2}$}

\begin{abstract}
1. Magister en Ciencias con mención en Psicología Clínica-Educativa Infantil y Adolescencial. Neuróloga Pediatra en el Hospital Regional Honorio Delgado Espinoza de Arequipa.

2. Bachiller en Medicina Humana. Residente de UCl Pediátrica en el Hospital Base Carlos Alberto Seguín Escobedo de Arequipa.
\end{abstract}

\section{RESUMEN}

La encefalitis por anticuerpos contra el receptor de N-metil-D-aspartato (NMDA) es un trastorno autoinmune caracterizado por síntomas neuropsiquiátricos, movimientos hipercinéticos e incluso hipoventilación central. Fue descrita por primera vez en el 2007 como parte de los síndromes neurológicos paraneoplásicos y es considerada una de las principales etiologías de encefalitis de origen no infeccioso. Cada vez es más reconocida como el cuadro encefalopático más común en mujeres jóvenes y niños, aunque frecuentemente sin asociación con tumores. Presentamos el caso de un niño de 2 años y 8 meses de edad con cuadro encefalopático subagudo que inició con crisis epilépticas seguidas de regresión neurológica y discinesias, y en quien el estudio del líquido cefalorraquídeo fue confirmatorio. La tomografía craneal mostró realce leptomeningeo y la angioresonancia cerebral evidenció asimetría en la distribución de las ramas de la arteria cerebral media sin compromiso en el parénquima cerebral. El paciente recibió tratamiento con corticoides y tras demostrarse la positividad de anticuerpos contra el receptor NMDA, se inició tratamiento con inmunoglobulina intravenosa, presentando reacción adversa medicamentosa. Posteriormente, el paciente recibió plasmaféresis como tratamiento de segunda línea.

Palabras clave: Anti- receptor NMDA, encefalitis, encefalitis anti receptor NMDA, N- metil-Daspartato, plasmaféresis.

\section{ABSTRACT}

Encephalitis by antibodies against the $\mathrm{N}$-methyl$\mathrm{D}$-aspartate (NMDA) receptor is an autoimmune disorder characterized by neuropsychiatric symptoms, hyperkinetic movements and even central hypoventilation. It was described for the first time in 2007 as part of the paraneoplastic neurological syndromes and is considered one of the main etiologies of encephalitis of noninfectious origin. It is increasingly recognized as the most common encephalopathic picture in young women and children, although frequently without association with tumors. We present the case of a 2-year-old and 8-month-old child with a subacute encephalopathic picture that began with epileptic seizures followed by neurological regression and dyskinesias, and in whom the study of cerebrospinal fluid was confirmatory. Cranial tomography showed leptomeningeal enhancement and cerebral angioresonance showed asymmetry in the distribution of the branches of the middle cerebral artery without involvement in the cerebral parenchyma. The patient was treated with corticosteroids and after demonstrating the positivity of antibodies against the NMDA receptor, treatment was started with intravenous immunoglobulin, presenting an adverse drug reaction. Subsequently, the patient received plasmapheresis as a second-line.

Key Words: Anti-NMDA anti-NMDA receptor encephalitis, encephalitis, N-methyl-Daspartate, plasmapheresis. 


\section{INTRODUCCIÓN}

La encefalitis por anticuerpos contra receptor de Nmetil-D-aspartato (NMDA) es un trastorno de origen autoinmune o paraneoplásico. La primera descripción de una encefalopatía autoinmune asociada a anticuerpos fue realizada por Corsellis e $\mathrm{col}^{(1)}$. Y en los últimos 10 años se han descrito diversos síndromes neurológicos originados por anticuerpos que actúan sobre antígenos expresados en la superficie celular. La encefalitis por anticuerpos contra el receptor de NMDA se presenta en pacientes de todas las edades, afectando comúnmente a mujeres jóvenes y niños con o sin teratomas. Los estudios epidemiológicos sugieren que el $65 \%$ de las encefalitis anti-NMDAR ocurren en pacientes menores de 18 años. En un estudio titulado Proyecto de Encefalitis de California en el año 2010 (2), se identificó que la encefalitis anti-NMDAR es cuatro veces más frecuente que el virus del herpes simple tipo 1 (HSV-1), virus del Nilo Occidental (WNV) o virus varicela- zoster (VZV) y fue la entidad líder identificada en esta cohorte. Las manifestaciones clínicas asociadas incluyen trastornos del comportamiento, crisis epilépticas, discinesias, trastornos del lenguaje, así como inestabilidad autonómica e hipoventilación. No existe un tratamiento estandarizado para estas entidades; sin embargo, se ha reportado que la implementación de terapias inmunomoduladoras permite una resolución más rápida del cuadro clínico. A continuación, se presenta el caso de un lactante mayor con una encefalitis por anticuerpos contra receptor de $\mathrm{N}$-metil-D-aspartato (NMDA) no asociada a un proceso neoplásico.

\section{CASO CLÍNICO}

Paciente varón de 2 años y 8 meses de edad, natural y procedente de Arequipa, que ingresa por emergencia del Hospital Regional Honorio Delgado con tiempo de enfermedad de 3 días, caracterizado por disminución de fuerza en hemicuerpo derecho, desviación de comisura labial ipsilateral, alteraciones en la marcha y lenguaje, deterioro progresivo del estado neurológico y presencia de convulsiones tónico clónicas generalizadas. El paciente no presentaba antecedentes prenatales, natales ni familiares patológicos. Durante el examen físico, estaba despierto y colaboraba parcialmente con la evaluación, buen estado de hidratación y nutrición, tórax simétrico, murmullo vesicular audible en ambos campos pulmonares, ruidos cardiacos rítmicos, normofonéticos sin soplos, abdomen sin visceromegalias, no adenopatías; en el examen neurológico se encontró paresia faciobraquiocrural derecha, marcha atáxica, disartria, movimientos coreoatetoides en miembro superior derecho, clonus en el hemicuerpo derecho sin trastornos de la sensibilidad. Al ingreso del paciente al hospital se documentó una crisis epiléptica focal compleja, con manifestaciones motoras en el hemicuerpo derecho. Los exámenes auxiliares arrojaron los siguientes datos: hemoglobina $12.3 \mathrm{gr} / \mathrm{dl}$, hemograma 5100 (segmentados 42\%, abastonados $4 \%$, linfocitos 50\%, monocitos $4 \%$ ), plaquetas 394000 ; perfil bioquímico, hepático y renal normales. La radiografía de tórax no mostró signos de proceso bronquial ni alveolar. El análisis del líquido cefalorraquídeo realizado al ingreso solo mostró glucosa de $47 \mathrm{mg} / \mathrm{dl}$, proteínas $1.81 \mathrm{~g} / \mathrm{L}$, leucocitos 06 cel.; coaglutiaciones, tinta china y cultivo de líquido cefalorraquídeo negativos. La serología para virus fue negativa tanto para herpes 1 y 2 , como para enterovirus. La ecografía abdominal total fue normal para la edad. La tomografía cerebral realizada al paciente mostró realce leptomeningeo (Figura 1). La angioresonancia cerebral realizada mostró la presencia de asimetría en la distribución de las ramas de la arteria cerebral media, sin mostrar otros signos de repercusión en el parénquima cerebral. Para el tratamiento de las crisis epilépticas, se inició esquema con fenitoína; posteriormente se adicionó haloperidol y midazolam por los episodios de agitación psicomotora, obteniéndose mala respuesta. Durante la hospitalización, el paciente recibió antibioticoterapia con ceftriaxona, a la que posteriormente se agregó aciclovir. Por cuadro clínico del paciente y evolución tórpida, se sospechó encefalitis autoinmune; consecuentemente se solicitó anticuerpos antiNMDAR en líquido cefalorraquídeo, los cuales resultaron positivos. Con este resultado se inició tratamiento específico a los 5 días de hospitalización con inmunoglobulina humana endovenosa, pero durante la primera administración el paciente presentó rash; por tanto, se suspendió la administración y se inició un protocolo de metilprednisolona endovenosa a $30 \mathrm{mg} / \mathrm{d}(1 \mathrm{mg} / \mathrm{kg} / \mathrm{d})$ por 3 días y se mantuvo con dexametasona endovenosa en dosis decreciente. Posteriormente, al no obtener mejoría clínica, el niño fue referido para realización de plasmaféresis e intubación por falla respiratoria. Se obtuvo buena respuesta clínica, siendo el paciente extubado a los 3 días. Luego se inició tratamiento con ácido valproico $150 \mathrm{mg}$ cada ocho horas vía oral, así como terapia física y rehabilitación. Pese a que la respuesta al tratamiento 
fue favorable, el paciente presentó secuelas en el área del lenguaje y ataxia.

\section{DISCUSIÓN}

Dentro del espectro de encefalopatías rápidamente progresivas, pero potencialmente reversibles, tenemos a las autoinmunes. Algunos de los elementos identificadores típicos asociados a la encefalitis por anticuerpos contra el receptor de N-metil-D-aspartato (NMDA) incluyen: 1) evolución rápidamente progresiva o fluctuante, 2) determinación de marcadores inflamatorios en el líquido cefalorraquídeo, presencia de un anticuerpo neural específico y 3 ) en algunas ocasiones, evidencia clínica o serológica de autoinmunidad coexistente ${ }^{(3)}$. La producción de autoanticuerpos puede estar relacionada con una neoplasia o puede ocurrir en el curso de un trastorno autoinmune subyacente. Sin embargo, esta condición no se cumple en todos los casos, principalmente en los jóvenes. Los receptores anti-NMDA existen como estructuras heterotetraméricas o pentaméricas, las cuales han sido clasificadas en 5 subunidades (NR1 y NR2A-D) ${ }^{(4 /)(5)}$. Su densidad es mayor a nivel del hipocampo y el lóbulo frontal, lo cual explica las características clínicas de presentación. La encefalitis por anticuerpos contra el receptor de N-metil-Daspartato (NMDA) es una entidad clínica descrita por primera vez en 2007 como parte de los síndromes neurológicos paraneoplásicos. Es en esta condición donde se desarrollan autoanticuerpos que se adhieren a la superficie externa del receptor, específicamente a la subunidad NR1. Esto desencadena la secuencia de mecanismos inmunomediados que determinan la fisiopatología de la afección. No hay datos fidedignos concernientes a la prevalencia e incidencia de esta enfermedad. Sin embargo, el hecho de aumentar la cantidad de casos reportados, indica que es más frecuente de lo estimado. De acuerdo a las series de pacientes se reporta un aproximado de 1 a $4 \%$ en la población de pacientes con encefalitis de causa desconocida ${ }^{(5)}$. Un elemento bien documentado es la alta prevalencia en pacientes de sexo femenino; ya que se ha reportado que de un $80 \%$ de los casos, la mayor asociación se ha establecido en niñas y adolescentes. Dentro de las teorías inmunogénicas resalta el componente paraneoplásico asociado; el cual es evidenciado por la asociación entre neoplasias de ovario (específicamente teratoma de ovario) con la producción de anticuerpos contra el receptor NMDA. Es importante destacar que esta asociación se ha evidenciado en múltiples estudios ${ }^{(6)(7)}$.
En el contexto del estudio de los pacientes con encefalitis de causa autoinmune, las enfermedades infecciosas son uno de los elementos diferenciales a descartar. Se ha visto en pocos pacientes la asociación con infecciones previas o concomitantes; sin embargo, no se ha podido demostrar inmunidad cruzada. De igual manera, se ha establecido cierta predisposición a otras condiciones autoinmunes, con el hallazgo ocasional concomitante con anticuerpos antinúcleo o antiperoxidasa, pero no hay suficiente evidencia para soportar esta relación ${ }^{(6)(8)}$. La disfunción neurológica inmunomediada, implica cierta reversibilidad, y los anticuerpos descritos son predominantemente de tipo IgG1 y en menor grado IgG3 ${ }^{(9)}$. El mecanismo básico descrito, corresponde a la unión de los anticuerpos a los receptores con la consecuente disminución de la densidad total de receptores expuesto. Los principales elementos expuestos señalan que estos anticuerpos causan una disminución reversible y selectiva de los receptores NMDA, así como de su densidad y localización en la terminal sináptica. Esta disminución implica internalización de los anticuerpos adheridos al receptor. El síndrome clínico ha sido ampliamente descrito por Dalmau y colaboradores ${ }^{(7)}$, al igual que las series de casos descritas en Japón ${ }^{(7)}$. Cerca de un $70 \%$ de pacientes pueden tener un pródromo caracterizado por cefalea, fiebre, náuseas, vómitos, diarrea, síntomas respiratorios superiores, con un período promedio de 5 días. Posteriormente, se describe una fase psicótica en donde se observan episodios de ansiedad, insomnio, alucinaciones, manías, hiperreligiosidad y paranoia. La tercera fase implica períodos de poca respuesta en donde se ha descrito trastornos del lenguaje caracterizados por disminución de la producción, ecolalia y ecopraxia que pueden evolucionar al franco mutismo, lo cual no se puede asignar a un componente afásico cortical. Otras manifestaciones de esta etapa pueden ser bradiquinesia, síntomas similares a catalepsia y poca interacción social. La cuarta fase implica períodos de hiperquinesia, en donde se suelen presentar disquinesias orofaciales, posturas distónicas, movimientos coreoatetoides ${ }^{(7)}$; adicionalmente, el comportamiento puede ser violento o hipersexual en algunos casos. En esta etapa pueden presentarse crisis epilépticas, y algunos pacientes pueden tener inestabilidad autonómica (bradicardia, fluctuación de presión arterial, hipertermia o diaforesis). La condición clínica relacionada con hipofunción al disminuir la disponibilidad de receptores ha sido adicionalmente documentada con el uso de antagonistas (Fenciclidina y ketamina) de los receptores NMDA ${ }^{(10)(11)}$. Una visión esquemática establece que esta disminución puede 
afectar vías dopaminérgicas, noradrenérgicas y colinérgicas, lo que se puede manifestar como alteraciones autonómicas, así como inactivación de neuronas gabaérgicas. Esto puede aumentar el glutamato extracelular conllevando a la aparición de vías excitatorias desinhibidas que a nivel frontoestriatal puede manifestarse como síntomas positivos o negativos de un episodio psicótico. La misma inactivación gabaérgicas puede afectar núcleos generadores centrales de patrones motores del tallo cerebral, pudiéndose manifestar con movimientos semirítmicos en musculatura bulbar de extremidades o truncal. Por último, la hipofunción dirigida a las zonas del control de la respiración bulbar, puede llevar a disfunción respiratoria e hipoventilación.

El examen físico de los pacientes revela una encefalopatía difusa, lo cual indica disfunción de estructuras subcorticales, regiones límbicas, amígdala y circuitos frontoestriatales. Los pacientes sin lesiones tumorales subyacentes suelen tener períodos de inconsciencia y confusión más prolongados. Los estudios de líquido cefalorraquídeo suelen demostrar una pleocitosis linfocitaria ${ }^{(12)}$, aunque inicialmente puede ser normal hasta en un $80 \%$ de los casos. La proteinorraquia suele elevarse discretamente, con una glucorraquia normal y hasta en un $60 \%$ de los casos, puede presentar bandas oligoclonales. El electroencefalograma suele presentarse con un enlentecimiento difuso, así como actividad desorganizada hasta actividad epileptógena en algunos casos. En estado catatónico suele predominar la actividad lenta continua con ritmos delta-theta ${ }^{(12)}$. La resonancia magnética cerebral suele ser poco relevante hasta en un $50 \%$ de los casos, mientras que en algunos pacientes se puede observar hiperintensidad en secuencias T2 y FLAIR a nivel del hipocampo, cerebelo, corteza frontobasal, ínsula, ganglios basales y tallo cerebral. Algunos pacientes que cursan con epilepsia refractaria pueden tener atrofia cerebral. El estudio ideal confirmatorio en estos casos, tal como se halló en nuestro paciente, corresponde a la detección en el líquido cefalorraquídeo, de anticuerpos contra el receptor NMDA, que correlacionan mucho mejor que los detectados en suero, ya que estos pueden desaparecer con el tiempo, con el uso de gammaglobulina o la exposición a plasmaféresis ${ }^{(13)(14)}$.

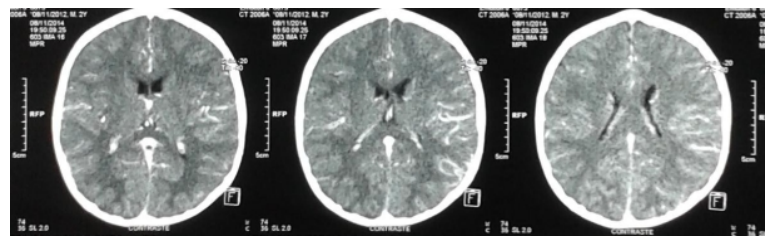

Figura 1. TEM Cerebral con contraste que mostró realce leptomeningeo

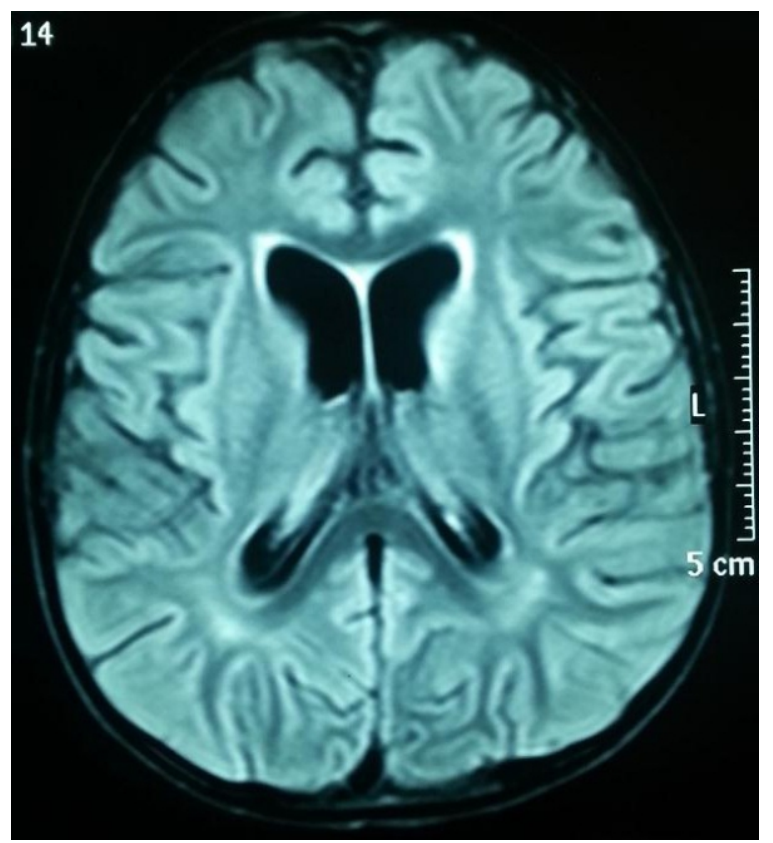

Figura 2. Secuencia FLAIR axial con incremento del diámetro ventricular y surcos pronunciados compatibles con atrofia difusa

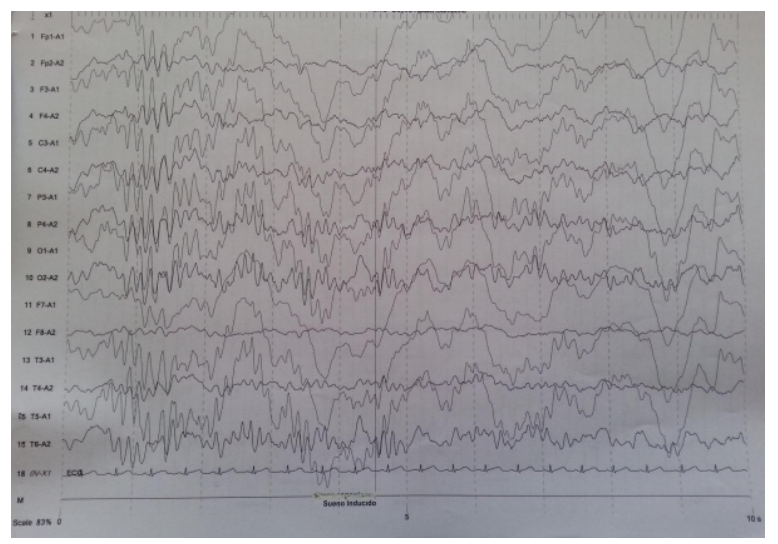

Figura 3. En el electroencefalograma se encontró actividad epiléptica bilateral con enlentecimiento difuso 


\section{REFERENCIAS BIBLIOGRÁFICAS}

1. Corsellis, J A., et al. "'Limbic Encephalitis" and Its Association with Carcinoma." Brain: a Journal of Neurology, vol. 91, no. 3, 1968, pp. 481-96.

2. Mary S. Gable, Heather Sheriff, Josep Dalmau, Drake H. Tilley, Carol A. Glaser; The Frequency of Autoimmune N-Methyl-DAspartate Receptor Encephalitis Surpasses That of Individual Viral Etiologies in Young Individuals Enrolled in the California Encephalitis Project. Clin. Infect. Dis. [internet]. 2012; 54(7): $\quad 899-904$, Dis pon i ble en : https://doi.org/10.1093/cid/cir1038.

3. McKeon A, Vanda L, Pittock S. Immunotherapy responsive dementias and encephalopathies. Continuum Lifelong Learning Neurol. 2010; 16: 80-101.

4. Arundine M, Tymlanski M. Molecular mechanisms of glutamate-dependent neurodegeneration in ischemia and traumatic brain injury. Cell Mol Life Sci. 2004; 61: 657-68.

5. Meldrum B. Glutamate as a neurotransmitter in the brain: review of physiology and pathology. J. Nutr. 2000; 130: 1007-15.

6. Dalmau J, Lancaster E, Martínez-Hernández E, Rosenfeld Myrna, Balice-Gordon R. Clinical experience and laboratory investigations in patients with anti-NMDAR encephalitis. Lancet Neurol. 2011; 10:63-74.

7. Lizuka T, Sakai F, Ide T, Monzen T, Yoshii S, ligaya M, et al. Anti-NMDA receptor encephalitis in Japan: long-term outcome without tumor removal. Neurology. 2008; 70:504-11.

8. Florance NR, Davis RL, Lam C, Szperka A, Zhou L, Ahmad S, et al. Anti-N-methyl-D-aspartate receptor (NMDAR) encephalitis

9. Tüzün E, Zhou L, Baehring JM, Bannykh S, Rosenfeld MR, Dalmau J. Evidence for antibody mediated pathogenesis in anti-NMDAR encephalitis associated with ovarian teratoma. ActaNeuropathol. 2009; 118:737-43.

10. Jentsch JD, Roth $\mathrm{RH}$. The neuropsychopharmacology of phencyclidine from NMDA receptor hypofunction to the dopamine hypothesis of schizophrenia.

Neuropsychopharmacology. 1999; 20:201-5.

11. Kapur S, Seeman P. NMDA receptor antagonists ketamine and PCP have direct effects on the Dopamine D2 and serotonin 5-HT2 receptors-implications for models of schizophrenia. Molecular Psychiatry. 2002; 7:837-44.

12. Gable MS, Gavali S, Radner A, Tilley DH, Lee B, Dyner L, et al. Anti-NMDA receptor encephalitis: report of ten cases and comparison with viral encephalitis. Eur J ClinMicrobiol Infect Dis. 2009; 28:1421-9.

13. Prüs $H$, Dalmau J, Harms L, Höltje M, Anhert-Hilger $F$, Borowski K, et al. Retrospective analysis of NMDA receptor antibodies in encephalitis of unknown origin. Neurology. 2010; 75:1735-9.

14. Breese E, Dalmau J, Vanda L, Apiwattanakul, Sokol D. Anti-N-methyl-D-Aspartate receptor encephalitis: early treatment is beneficial. PediatrNeurol. 2010; 42:213-4.

\section{Correspondencia}

Ana M. Álvarez Sanz

E-mail: amalvarezs@yahoo.es

Fecha de recepción: 02 de setiembre 2018

Fecha de aceptación: 22 de febrero de 2019 